\title{
Quantitative sperm characteristics of Tankwa goats with special reference to hyperactivated motility
}

\author{
A. Ngcauzele 1 , G. van der Horst ${ }^{1,2}$, A. Kotze $e^{2,3}$, T. Jonker ${ }^{4} \&$ L. Maree ${ }^{1,2 \#}$ \\ ${ }^{1}$ Department of Medical Bioscience, University of the Western Cape, P/Bag X17, Bellville, 7535, South Africa \\ ${ }^{2}$ National Zoological Garden, South African National Biodiversity Institute, PO Box 754, Pretoria, 0001, South Africa \\ ${ }^{3}$ Genetics Department, University of the Free Sate, PO Box 339, Bloemfontein 9300, South Africa \\ ${ }^{4}$ Northern Cape Department of Agriculture, Land Reform and Rural Development, Private Bag X9, Jan Kempdorp, 8550 , \\ South Africa
}

(Submitted 28 January 2020; Accepted 4 July 2020; Published 26 October 2020)

\begin{abstract}
Copyright resides with the authors in terms of the Creative Commons Attribution 4.0 South African Licence.
See: http://creativecommons.org/licenses/by/4.0/za

Condition of use: The user may copy, distribute, transmit and adapt the work, but must recognise the authors and the South African Journal of Animal Science.
\end{abstract}

\begin{abstract}
Computer-assisted semen analysis (CASA) is an automated and objective method of evaluating structural (e.g. morphology) and functional sperm parameters (e.g. motility and hyperactivation). Sperm hyperactivation is essential for successful fertilization and is thus an important aspect in determining the fertility potential of a male. In the current study, CASA was used for standard semen analysis and for comparison of the ability of phosphate buffered saline (PBS), BO sperm wash (10 mM caffeine), 4\% lignocaine, and $5 \mathrm{mM}$ procaine hydrochloride to induce hyperactivation in Tankwa goat spermatozoa. Twenty-nine ejaculates were collected from randomly selected male goats by electroejaculation. Although none of the four media affected percentage total sperm motility, lignocaine caused a significant decrease $(P$ $>0.05)$ in percentage progressive motility. Exposure to procaine resulted in an increase in swimming speed $(P \leq 0.05)$ and star-spin motility tracks, which are typical of sperm hyperactivation. Using PBS and procaine motility data from individually selected spermatozoa, receiver operator characteristic curves were constructed to distinguish the kinematic parameters employed as cut-off values for sperm hyperactivation. PBS and BO sperm wash did not induce hyperactivation $(0.1 \pm 0.2 \%$ and $0.04 \pm 0.2 \%$ respectively), while lignocaine induced little hyperactivation $(3.4 \pm 3.0 \%)$ and procaine hydrochloride had the highest percentage hyperactivation $(25.3 \pm 13.6 \%)$. The large variation in hyperactivation $(0-54.5 \%)$ may reflect inter-individual differences in sperm quality among these males. This study indicated procaine hydrochloride was the most promising hyperactivation-inducing medium for Tankwa goat spermatozoa and should be considered for similar assessments in other animal species.
\end{abstract}

Keywords: computer-aided sperm analysis, procaine hydrochloride, sperm kinematics, sperm morphometry, sperm motility

\#Corresponding author: Imaree@uwc.ac.za

\section{Introduction}

Tankwa goats originated from an isolated population of feral goats in the south-western region of the arid Karoo district, mainly Tankwa Karoo National Park (Northern Cape, South Africa), where they are thought to have been roaming free for more than 80 years without human interference. At least two studies have shown that the Tankwa goat is closely related to other indigenous goat breeds (e.g. Boer and South African village goats) and has similar genetic diversity (Kotze et al., 2014; Ncube et al., 2016). Kotze et al. (2014) compared the Tankwa goat with commercial breeds such as Boer, Angora, and Saanen goats, and concluded that the Tankwa goat is a unique genetic resource that needs to be managed optimally. An understanding of their reproductive biology could add valuable information to conservation strategies and the breeding potential of Tankwa goats.

Semen and sperm quality assessments are important in predicting the fertility potential of males and are based primarily on the manual evaluation of conventional parameters such as semen volume, sperm motility, concentration, morphology, viability, and acrosome integrity (Verstegen et al., 2002). During the past 
three decades several commercial computer-aided sperm analysis (CASA) systems have been developed, primarily to promote standardized and quantitative evaluation of semen samples. CASA allows for faster, accurate and more detailed results and eliminates the subjective biases that are inherent in manual semen analysis (Coetzee et al., 2001; Van der Horst et al., 2018a).

Mammalian spermatozoa cannot fertilize oocytes immediately after ejaculation. A series of changes must occur in the physical and chemical properties of the sperm head and the tail plasma membrane before they are able to penetrate the zona pellucida and bind to the oocyte (Hunter, 2012; Gervasi \& Visconti, 2016). Collectively these changes are termed 'capacitation' and are associated with both hyperactivated motility and the spermatozoon's ability to undergo the acrosome reaction (Visconti et al., 2011; Puga Molina et al., 2018).

Spermatozoa generally have two phases of motility, namely active and hyperactivated. Active motility occurs in a fresh ejaculate and displays a symmetrical low-amplitude waveform, which assists spermatozoa to swim in a straight line (Henkel et al., 2005). During sperm hyperactivation, the flagellar beat pattern is characterized by wide amplitude, large lateral movements of the head and the flagellum, which is coupled with fast, non-progressive motility, which is also referred to as the 'star-spin' movement (Yanagimachi, 1994; Ho \& Suarez, 2001). Hyperactivation is thought to provide strong thrusting power to the spermatozoa while passing through the viscoelastic female reproductive tract and the egg investments, particularly the zona pellucida (Ardon et al., 2016; Suarez \& Wu, 2017). The crucial signal for the induction of hyperactivation appears to be an increase in intracellular levels of the calcium ion $\left(\mathrm{Ca}^{2+}\right)$ (Strünker et al., 2011; Sumigama et al., 2015), through the opening of pH-sensitive cation channels of sperm (CatSper) in the flagellar plasma membrane (Alasmari et al., 2013; Tamburrino et al., 2015) and the release of $\mathrm{Ca}^{2+}$ from stores in the sperm neck and midpiece region (Ho \& Suarez, 2003; Costello et al., 2009).

Assessment of hyperactivation can serve as a biological marker to evaluate the functional capabilities and fertility potential of spermatozoa because of its association with fertilization success and live birth outcomes in humans and domesticated animal species (McPartlin et al., 2009; Alasmari et al., 2013; Williams et al., 2015). CASA has been used to establish the percentage hyperactive flagellar movement according to species-specific kinematic cut-off values set by the user for hyperactivation (Mortimer et al., 2015). Several chemicals have been used to induce and measure hyperactivation in vitro objectively, such as progesterone (Strünker et al., 2011), caffeine (Colás et al., 2010), procaine hydrochloride (McPartlin et al., 2009) and 4-aminopyridine (Bedu-Addo et al., 2008).

Except for a study on the seminal plasma constituents of Tankwa goats (Ramukhithi et al., 2018), there is not sufficient information about the reproductive biology of these goats to select males for future breeding and smallholder farming. The purpose of this study was to provide a more detailed investigation of male fertility by employing objective and novel techniques to evaluate the semen characteristics and sperm functionality of Tankwa goats. Computer-assisted semen analysis was used to quantify semen parameters for Tankwa goats and compare the abilities of four media and chemicals to induce sperm hyperactivation. Because kinematic parameter cut-off values for hyperactivation were not available for goat spermatozoa, an imperative objective was to determine and subsequently apply such values to Tankwa goat spermatozoa and assess their fertility potential.

\section{Materials and methods}

All procedures were performed in agreement with and approved by the Animal Ethics Committees of the University of the Western Cape (Project number AR17/5/29) and the Research Ethics and Scientific Committee of the National Zoological Gardens (Project number NZG/RES/P17/34).

Randomly selected and sexually mature male Tankwa goats from Carnarvon Research Station (Northern Cape Department of Agriculture, Land Reform and Rural Development) were used for this study. The research station is located at $30^{\circ} 95^{\prime} \mathrm{S}$ and $22^{\circ} 13^{\prime} \mathrm{E}$ in Carnarvon, South Africa, and is situated at an altitude of $1234 \mathrm{~m}$ above sea level. The free-roaming male goats were held in two large permanent camps (total size of $1000 \mathrm{ha}$ ) together with females (not limiting ejaculation prior to sampling) and had free access to water and natural vegetation. The research station is located in the Nama-Karoo Biome and the vegetation type is classified as Western Upper Karoo (NKu 1), consisting mainly of a mixture of small-leaved shrubs, shrubby succulents, drought-resistant grasses and few tree species (Mucina \& Rutherford, 2006).

Semen samples $(n=29)$ were collected during the summer season (February) over a three-hour period in the early morning. Males were restrained in a recumbent sitting position, and samples were collected into sterile pre-warmed $\left(37^{\circ} \mathrm{C}\right) 50 \mathrm{ml}$ polypropylene tubes. Semen was produced by means of periprostatic electro-stimulation using an Eltoro 3 rectal probe electro-ejaculator (Electronic Research Group, Midrand, South Africa), according to a method adapted from Malejane et al. (2014). Electrical stimulation (5$15 \mathrm{~V}, 500 \mathrm{~mA}$ ) was applied at intervals of three to five seconds, and alternated with rest periods of three to five seconds, for a maximum of six times. During stimulations, the current was increased gradually until an 
ejaculate was obtained within 1-2 minutes (Noakes et al., 2009). Ejaculates were kept at $37^{\circ} \mathrm{C}$ immediately after collection and for the duration of all experimental procedures.

A basic semen analysis was performed to evaluate the quantity and quality of each sample by assessing semen volume, $\mathrm{pH}$, macro movement, sperm concentration, sperm motility (including percentages total motility, progressive motility, rapid-, medium- and slow-swimming spermatozoa) and sperm vitality. The swimming-speed subpopulations were determined with curvilinear velocity (VCL) cut-off values of $20<80>180$ $\mu \mathrm{m} / \mathrm{s}$ to identify slow-, medium- and rapid-swimming spermatozoa (Maree \& Van der Horst, 2013). Sperm concentration and motility were evaluated by placing $3 \mu$ semen into a preheated $\left(37^{\circ} \mathrm{C}\right)$ Leja four-chamber slide (Leja Products B.V., Nieuw-Vennep, The Netherlands). Fields were randomly captured at 50 frames per second using the motility/concentration module of the sperm class analyser $\left(\mathrm{SCA}^{\circledR}\right.$, version 6.0, 2018, Microptic S.L., Barcelona, Spain) CASA system. Additionally, a Basler Ace ACA-1300-200uc digital camera (Microptic S.L., Barcelona, Spain) was mounted on a Nikon Eclipse 50i microscope (IMP, Cape Town, South Africa), equipped with a 10x objective, using negative phase contrast optics and a heated stage $\left(37^{\circ} \mathrm{C}\right)$. At least two fields were captured and analysed for each semen sample, including a minimum of 200 motile spermatozoa in total.

Sperm vitality was evaluated using BrightVit ${ }^{\circledR}$, a nigrosin-eosin stain (Microptic SL, Barcelona, Spain). A volume of $5 \mu \mathrm{l}$ semen was mixed with $15 \mu \mathrm{l}$ preheated BrightVit and incubated for 30 seconds before smears were made. Mounted preparations were viewed with a $\times 40$ objective, bright field optics and a blue filter using the same microscope and camera as for motility analysis. Vitality of at least 100 spermatozoa from each semen sample was assessed with the vitality module of SCA software (version 6.0, 2018).

Sperm morphometry and morphology were assessed and quantified using SpermBlue (Microptic SL, Barcelona, Spain), a universal stain for automated sperm morphology analysis (ASMA) (Van der Horst \& Maree, 2009). Stained slides were left to air dry overnight and were then mounted with a coverslip using DPX mounting medium. Sperm morphometry was assessed using a 60x objective on a Nikon Eclipse 50i microscope (IMP, Cape Town, South Africa) and a Basler Ace ACA-1300-200uc digital camera (Microptic S.L., Barcelona, Spain). Images of at least 100 spermatozoa were captured analysed with the morphology module of the SCA software (version 6.0, 2018).

Eleven sperm morphometry parameters were measured by SCA, as indicated in Table 1. Because of the lack of reference values for assessing the percentage Tankwa goat spermatozoa with normal morphology, cut-off values for normal morphology were determined as described by Van der Horst et al. (2018b). Minimum and maximum values for each parameter (Table 1) were derived from $90 \%$ confidence intervals to generate a Tankwa goat configuration function for evaluating normal sperm morphometry. Normal sperm head morphometry values established by Gravance et al. (1995) for Alpine goats fall within the current measured ranges for Tankwa goats, except for head area.

Table 1 Sperm morphometry measurements used in determining percentage normal morphology for Tankwa goat spermatozoa

\begin{tabular}{llcc}
\hline Sperm component & Measurement & Minimum & Maximum \\
\hline \multirow{2}{*}{ Head } & Length, $\mu \mathrm{m}$ & 7.45 & 10.87 \\
& Width, $\mu \mathrm{m}$ & 3.50 & 5.10 \\
& Area, $\mu \mathrm{m}^{2}$ & 26.30 & 51.52 \\
& Perimeter, $\mu \mathrm{m}$ & 16.67 & 23.59 \\
& Ellipticity & 1.78 & 2.53 \\
& Elongation & 0.28 & 0.43 \\
& Roughness & 0.79 & 1.75 \\
& Regularity & 0.61 & 0.97 \\
& Acrosome, \% & 47 & 100 \\
& Vacuoles, \% & 0 & 20 \\
Midpiece & Width, $\mu \mathrm{m}$ & 0 & 1.99 \\
& Area, $\mu \mathrm{m}^{2}$ & 0 & 27.50 \\
\hline
\end{tabular}


Because mammalian spermatozoa react differently to physiological media that are used to dilute and induce capacitation, it was decided to first evaluate the effect of selected media on sperm motility. Spermatozoa were exposed to four pre-warmed $\left(37^{\circ} \mathrm{C}\right)$ media, namely phosphate buffered saline (PBS) (control), BO sperm wash (containing $10 \mathrm{mM}$ caffeine, as proposed by Brackett and Oliphant (1975)), 4\% lignocaine in PBS (G. van der Horst, personal communication, 2016) and $5 \mathrm{mM}$ procaine hydrochloride in PBS (McPartlin et al., 2009). According to the flush technique (Boshoff et al., 2018), $2 \mu \mathrm{l}$ of each medium was used to flush $1 \mu \mathrm{l}$ semen into the chambers of a Leja slide (Leja Products B.V., Nieuw-Vennep, The Netherlands), while keeping the slide on a heated stage. Sperm motility was evaluated for each semen sample five minutes after exposure to the media. In addition to the sperm motility percentages, eight kinematic parameters were measured, namely VCL, VAP, straight-line velocity (VSL), straightness (STR) $(\mathrm{STR}=\mathrm{VSL} / \mathrm{VAP})$, linearity $(\mathrm{LIN})(\mathrm{LIN}=\mathrm{VSL} / \mathrm{VCL})$, wobble $(\mathrm{WOB})(\mathrm{WOB}=\mathrm{VAP} / \mathrm{VCL})$, amplitude of lateral head displacement (ALH), and beat-cross frequency (BCF). The ALH parameter was measured as half the width of the VCL track and not as the full VCL wave or doubling of the riser values (risers method) as described by Mortimer $(1994,1997)$.

Sperm kinematic parameter cut-off values for identifying Tankwa goat spermatozoa that displayed hyperactive motility were determined with a method described by Mortimer et al. (2015). First, individual spermatozoa from each semen sample $(n=290$ in total; 145 from PBS and 145 from procaine medium) were selected upon displaying typical activated linear swimming patterns after exposure to PBS or typical hyperactivated star-spin swimming patterns after exposure to procaine hydrochloride, respectively (Figure 1). Kinematic data of spermatozoa selected through such visual pattern recognition were used to construct receiver operating characteristics (ROC) curves (DeLong et al., 1988) for each of the eight kinematic parameters. Only those parameters that displayed both high sensitivity and specificity $(>80 \%)$ when comparing the PBS and procaine treated samples were selected as cut-offs for hyperactivation. These cutoff values were used to create a sort function for Tankwa goat sperm hyperactivation in the SCA motility module.

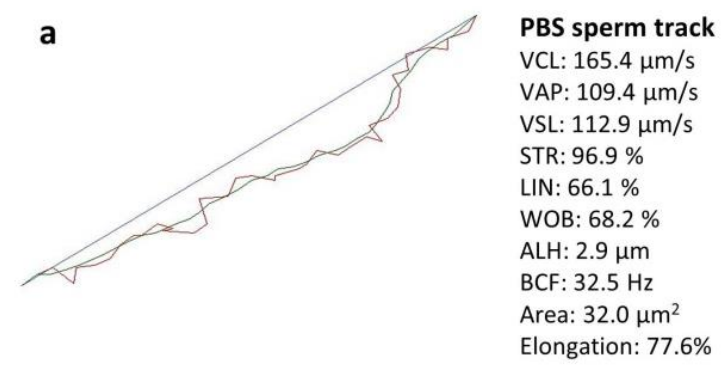

$50 \mu \mathrm{m}$

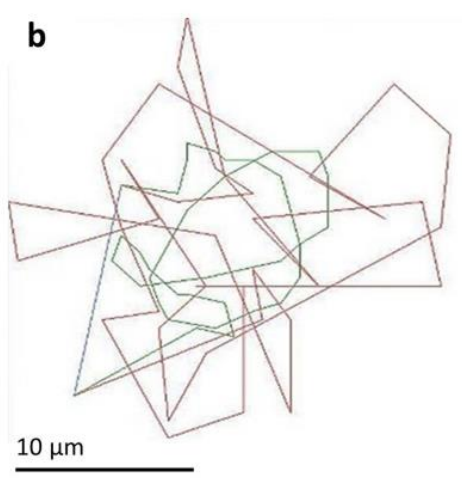

Procaine sperm track

VCL: $305.3 \mu \mathrm{m} / \mathrm{s}$

VAP: $99.8 \mu \mathrm{m} / \mathrm{s}$

VSL: $16.0 \mu \mathrm{m} / \mathrm{s}$

STR: $16.1 \%$

LIN : $5.3 \%$

WOB: $32.7 \%$

ALH: $10.4 \mu \mathrm{m}$

BCF: $9.4 \mathrm{~Hz}$

Area: $12.8 \mu \mathrm{m}^{2}$

Elongation: $68.8 \%$

Figure 1 Typical movement patterns of individual spermatozoa captured at 50 frames per second, a) Relatively straight-swimming track after PBS incubation, and b) star-spin track after procaine hydrochloride exposure

VCL: red line, VAP: green line, VSL: blue line. VCL: curvilinear velocity, VAP: average path velocity, VSL: straight-line velocity, STR: straightness, LIN: linearity, WOB: wobble, ALH: amplitude of lateral head displacement, BCF: beat cross frequency

All the data were collected and saved as CASA files, and then transferred to MedCalc software (version 12.3.0, 2018, Mariakerke, Belgium). Levene's test for equality of variances was applied and when $P$ $>0.05$, one-way analysis of variance analysis (ANOVA) was performed for parametric data distributions. Significant differences $(P \leq 0.05)$ indicated in the ANOVA table among groups were further analysed using the Student-Newman-Keuls test for pairwise comparisons. In subsets of data that appeared to have nonparametric data distributions, the Kruskal-Wallis test was used and, when required, the Mann-Whitney test for independent samples was applied. Correlation coefficients were also calculated between percentage sperm hyperactivation and all other semen and sperm characteristics. Data were represented as mean \pm standard deviation (SD) in the tables while $P \leq 0.05$ was considered significant. 


\section{Results and Discussion}

A mean volume of $1.3 \mathrm{~mL}$ Tankwa goat semen was collected during electro-ejaculations, while it ranged between $0.4 \mathrm{~mL}$ and $2.5 \mathrm{~mL}$ (Table 2) for all samples. The semen contained on average 2293.7 $\mathrm{x} 10^{6} / \mathrm{mL}$ spermatozoa and a total sperm count of $29.5 \pm 8.9 \times 10^{9}$, with a large range between the minimum $\left(35.2 \times 10^{6} / \mathrm{mL}\right)$ and maximum $\left(8540.0 \times 10^{6} / \mathrm{mL}\right)$ concentrations. The mean semen $\mathrm{pH}$ was $6.0 \pm 0.9$ and macro-movement of spermatozoa ranged between 2 and 5 (average $4.3 \pm 0.9$ ). Spermatozoa had a total motility of $83.7 \pm 10.5 \%$, of which $65.3 \%$ on average portrayed progressive motility characteristics. The three sperm subpopulations based on swimming speed included $12.8 \%$ rapid-swimming, $61.1 \%$ medium-swimming and $13.6 \%$ slow-swimming spermatozoa. Sperm vitality assessments revealed that semen contained $71.8 \pm$ $13.8 \%$ live spermatozoa.

Morphometry measurements indicated that Tankwa goat spermatozoa had a head length of $8.5 \pm 0.2$ $\mu \mathrm{m}$ and width of $4.0 \pm 0.1 \mu \mathrm{m}$, which contributed to a head area and perimeter of $35.3 \pm 2.6 \mu \mathrm{m}^{2}$ and $18.6 \pm$ $0.6 \mu \mathrm{m}$, respectively (Table 3 ). Head elongation, ellipticity, regularity and roughness had little variation among spermatozoa. The acrosome covered on average $55.6 \%$ of the sperm head. The two midpiece morphometrics showed a mean width of $1.1 \mu \mathrm{m}$ and a mean area of $10.9 \mu^{2}$. Using the cut-off morphometric values displayed in Table 1, ASMA revealed that $62.0 \pm 26.3 \%$ of Tankwa goat spermatozoa portrayed normal morphology. The values displayed in Table 1 and Table 3 are from different sperm populations.

Table 2 Semen characterization for Tankwa goat population $(n=29)$

\begin{tabular}{lrrrr}
\hline & Mean & Standard deviation & Minimum & Maximum \\
\hline Volume, mL & 1.3 & 0.5 & 0.4 & 2.5 \\
$\mathrm{pH}^{*}$ & 6.0 & 0.9 & 5.5 & 7.5 \\
Sperm concentration, $\times 10^{6} / \mathrm{mL}$ & 2293.7 & 1853.6 & 35.2 & 8540.0 \\
Total sperm count, $\times 10^{9}$ & 29.5 & 8.9 & 0.3 & 111.0 \\
Macro-movement & 4.3 & 0.9 & 2.0 & 5.0 \\
Total motility, \% & 83.7 & 10.5 & 59.0 & 96.1 \\
Progressive motility, \% & 65.3 & 13.3 & 38.9 & 85.3 \\
Rapid, \% & 12.8 & 11.3 & 2.6 & 43.1 \\
Medium, \% & 61.1 & 12.6 & 34.6 & 85.8 \\
Slow, \% & 13.6 & 11.8 & 0.8 & 53.5 \\
Vitality, \% & 71.8 & 13.8 & 39.0 & 94.0 \\
\hline
\end{tabular}

${ }^{*} \mathrm{n}=5$, Rapid: rapid-swimming sperm, Medium: medium-swimming sperm, Slow: slow-swimming sperm

Sperm motility percentages and the kinematic characteristics of spermatozoa exposed to the four media are displayed in Table 4. While no difference was found among the media for percentage total motility, the lignocaine-supplemented medium resulted in significantly lower percentage progressive motile spermatozoa (25.4\%) compared with the other media $(40.0-48.9 \%)$. Furthermore, the procainesupplemented medium resulted in the highest average percentage of rapid-swimming spermatozoa (44.4\%), whereas BO sperm wash had the lowest average for this parameter (6.2\%). Exposure to the procaine medium resulted in the highest averages for VCL and ALH compared with the other three media. Procaine and lignocaine also resulted in significantly lower average VSL, STR, LIN, WOB and BCF than PBS and BO sperm wash (Figure 2). Similar differences in the sperm kinematics were found when the effect of the media on three sperm subpopulations were evaluated (Table 5). These differences in sperm kinematics resulted in distinctive swimming tracks for the four media, with more linear patterns being seen in PBS and BO wash (Figures $3 \mathrm{a}$ and $3 \mathrm{~b}$ ) and more irregular circular or star-spin-type patterns being seen in lignocaine and procaine (Figures $3 \mathrm{c}$ and $3 \mathrm{~d}$ ). 
Table 3 Sperm morphometry and morphology for Tankwa goat spermatozoa $(n=7)$

\begin{tabular}{lrcrr}
\hline & Mean & Standard deviation & Minimum & Maximum \\
\hline Head length, $\mu \mathrm{m}$ & & & & \\
Head width, $\mu \mathrm{m}$ & 8.5 & 0.2 & 8.4 & 8.8 \\
Head area, $\mu \mathrm{m}^{2}$ & 4.0 & 0.1 & 3.9 & 4.2 \\
Head perimeter, $\mu \mathrm{m}$ & 35.3 & 2.6 & 32.5 & 39.1 \\
Head ellipticity & 18.6 & 0.6 & 17.5 & 19.3 \\
Head elongation & 2.1 & 0.04 & 2.0 & 2.2 \\
Head roughness & 0.4 & 0.01 & 0.3 & 0.4 \\
Head regularity & 1.3 & 0.1 & 1.2 & 1.4 \\
Midpiece width, $\mu \mathrm{m}$ & 0.8 & 0.04 & 0.7 & 0.8 \\
Midpiece area, $\mu \mathrm{m}^{2}$ & 1.1 & 0.1 & 1.0 & 1.3 \\
Acrosome coverage, \% & 10.9 & 3.0 & 7.1 & 15.8 \\
Normal morphology, \% & 55.6 & 1.1 & 54.6 & 57.8 \\
& 62.0 & 26.3 & 31.0 & 95.0 \\
\hline
\end{tabular}

Table 4 Sperm kinematic parameter measurements and percentage hyperactivation after exposure to phosphate buffered saline, BO sperm wash, $4 \%$ lignocaine and $5 \mathrm{mM}$ procaine hydrochloride

\begin{tabular}{|c|c|c|c|c|c|c|c|c|}
\hline \multirow{2}{*}{ Measurement } & \multicolumn{2}{|c|}{ PBS, $n=29$} & \multicolumn{2}{|c|}{ BO wash, $n=29$} & \multicolumn{2}{|c|}{ Lignocaine, $n=27$} & \multicolumn{2}{|c|}{ Procaine, $n=28$} \\
\hline & mean & SD & mean & SD & mean & SD & mean & SD \\
\hline Total motility, \% & 86.6 & 13.1 & 84.3 & 13.5 & 83.4 & 17.7 & 83.9 & 13.5 \\
\hline Progressive motility, \% & $48.9^{a}$ & 22.1 & $40.0^{\mathrm{a}}$ & 15.2 & $25.4^{\mathrm{b}}$ & 14.1 & $47.9^{\mathrm{a}}$ & 20.4 \\
\hline Rapid, \% & $13.0^{\mathrm{a}}$ & 11.6 & $6.2^{\mathrm{b}}$ & 6.1 & $17.7^{\mathrm{c}}$ & 13.4 & $44.4^{d}$ & 20.8 \\
\hline Medium, \% & $51.6^{\mathrm{a}}$ & 20.2 & $48.2^{\mathrm{a}}$ & 19.8 & $46.0^{\mathrm{a}}$ & 16.6 & $24.5^{\mathrm{b}}$ & 11.1 \\
\hline Slow, \% & $22.0^{\mathrm{a}}$ & 1.7 & $29.8^{\mathrm{b}}$ & 10.8 & $19.8^{c}$ & 13.1 & $15.0^{d}$ & 7.6 \\
\hline $\mathrm{VCL}, \mu \mathrm{m} / \mathrm{s}$ & $106.4^{\mathrm{a}}$ & 32.6 & $88.8^{\mathrm{b}}$ & 22.4 & $107.0^{c}$ & 31.1 & $149.0^{d}$ & 41.0 \\
\hline VSL, $\mu \mathrm{m} / \mathrm{s}$ & $55.5^{\mathrm{a}}$ & 21.0 & $45.7^{b}$ & 14.6 & $29.8^{\mathrm{C}}$ & 9.1 & $33.7^{\mathrm{C}}$ & 9.3 \\
\hline $\mathrm{VAP}, \mu \mathrm{m} / \mathrm{s}$ & $67.4^{\mathrm{a}}$ & 23.1 & $56.1^{\mathrm{b}}$ & 16.4 & $53.3^{b}$ & 15.6 & $67.8^{\mathrm{a}}$ & 18.0 \\
\hline STR, \% & $71.1^{\mathrm{a}}$ & 12.2 & $71.1^{\mathrm{a}}$ & 9.6 & $50.4^{b}$ & 8.2 & $46.2^{b}$ & 6.9 \\
\hline LIN, \% & $46.6^{a}$ & 12.5 & $45.8^{a}$ & 11.4 & $27.7^{b}$ & 6.7 & $26.5^{b}$ & 6.5 \\
\hline WOB, \% & $58.9^{a}$ & 10.2 & $58.5^{a}$ & 10.1 & $48.1^{b}$ & 5.9 & $47.0_{b}$ & 5.9 \\
\hline $\mathrm{ALH} \mu \mathrm{m}$ & $2.2^{\mathrm{a}}$ & 0.6 & $1.9^{a}$ & 0.4 & $3.0^{b}$ & 0.8 & $4.0^{c}$ & 1.0 \\
\hline $\mathrm{BCF} \mathrm{Hz}$ & $21.9^{a}$ & 6.0 & $21.5^{\mathrm{a}}$ & 5.2 & $15.2^{b}$ & 3.8 & $12.3^{c}$ & 2.7 \\
\hline $\mathrm{HA}, \%$ & $0.1^{\mathrm{a}}$ & 0.2 & $0.04^{b}$ & 0.2 & $3.4^{q}$ & 3.0 & $25.3^{b}$ & 13.6 \\
\hline
\end{tabular}

${ }^{\mathrm{a}-\mathrm{a}}$ Within a row means with a common superscript did not differ at $P=0.05$

BO wash: $10 \mathrm{mM}$ caffeine, Rapid: rapid-swimming sperm, Medium: medium-swimming sperm, Slow: slow-swimming sperm, VCL: curvilinear velocity, VSL: straight-line velocity, VAP: average path velocity, STR: straightness, LIN: linearity, WOB: wobble, ALH: amplitude of lateral head displacement, BCF: beat cross frequency, HA: hyperactivation. 


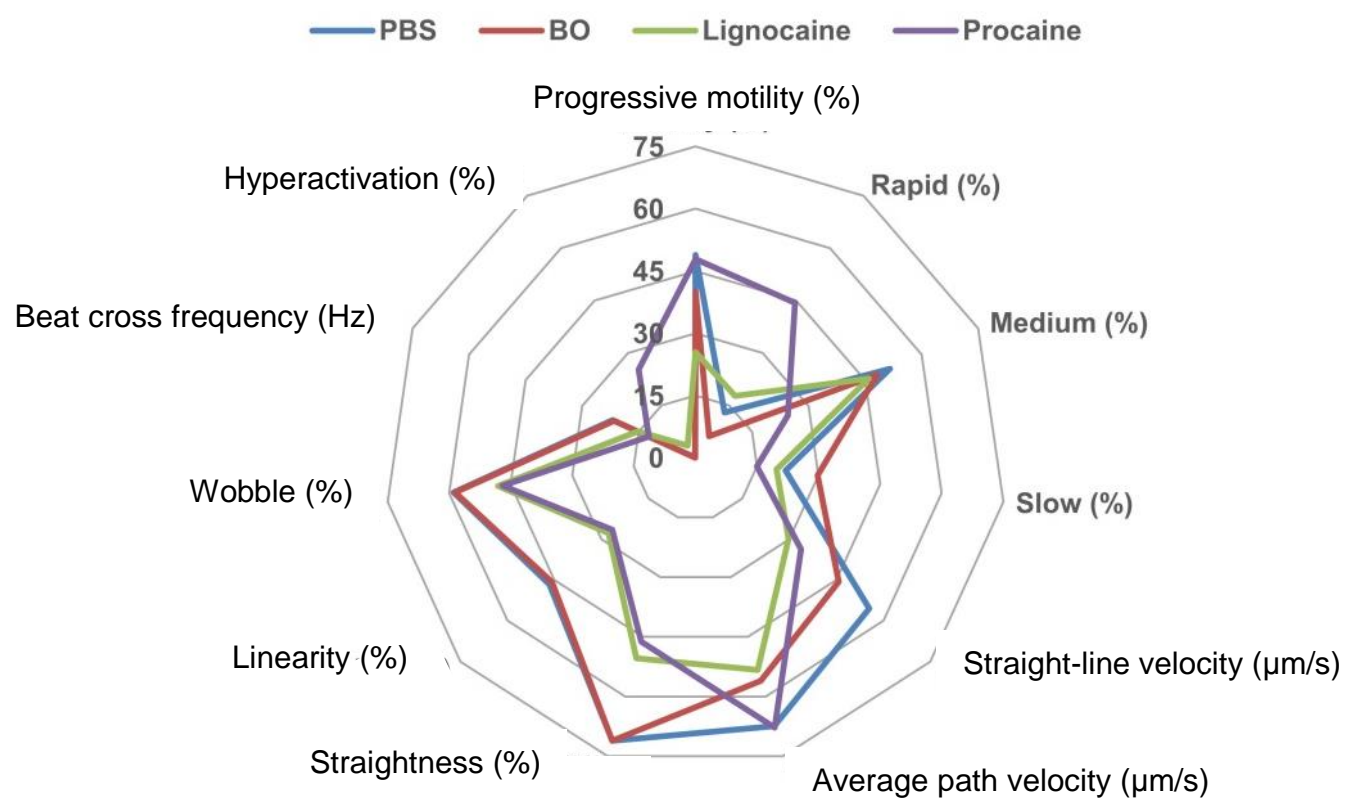

Figure 2 Radar plot illustrating differences in average values for progressive motility, rapid-swimming, medium-swimming, slow-swimming spermatozoa, straight-line velocity, average path velocity, straightness, linearity, wobble, beat cross frequency, and hyperactivation for hyperactivated sperm in phosphate buffered saline, sperm wash containing $10 \mathrm{mM}$ caffeine, lignocaine, and procaine hydrochloride
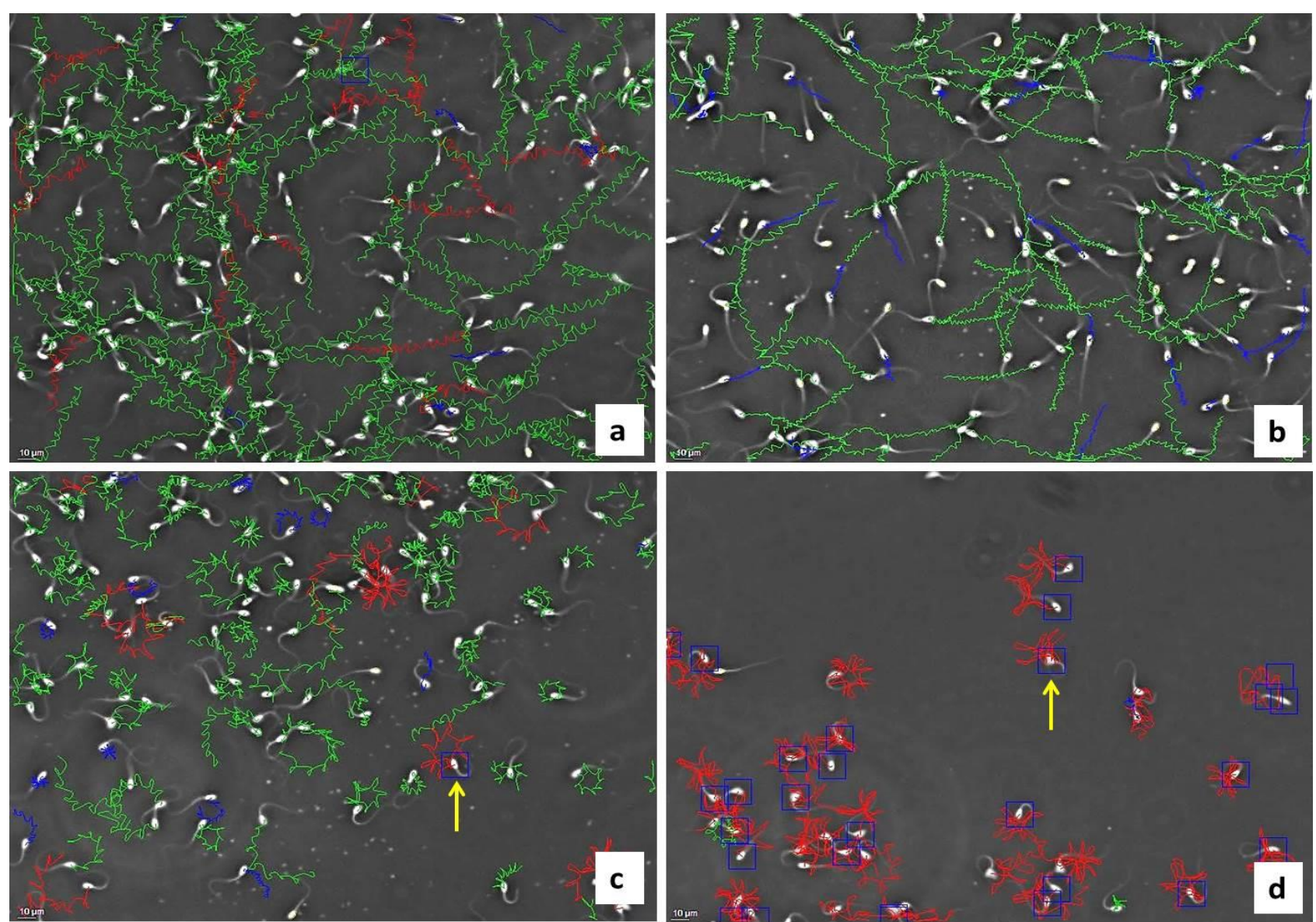

Figure 3 Analysed Tankwa goat motility fields after exposure to a) PBS, b) BO sperm wash, c) lignocaine, and d) procaine hydrochloride, using 100x magnification

Red: rapid-progressive spermatozoa, green: medium-progressive spermatozoa, blue: non-progressive spermatozoa, blue box = hyperactivated spermatozoa (see yellow arrows for examples) 
Table 5 Sperm kinematic parameters measurements (mean \pm SD) for three sperm subpopulations (rapid-, medium- and slow-swimming speed) after exposure to phosphate buffered saline, BO sperm wash, 4\% lignocaine and $5 \mathrm{mM}$ procaine hydrochloride

\begin{tabular}{|c|c|c|c|c|c|c|c|c|}
\hline \multirow{2}{*}{ Measurement } & \multicolumn{2}{|c|}{ PBS, $n=29$} & \multicolumn{2}{|c|}{ BO wash, $n=29$} & \multicolumn{2}{|c|}{ Lignocaine, $n=27$} & \multicolumn{2}{|c|}{ Procaine, $n=28$} \\
\hline & mean & SD & mean & SD & mean & SD & mean & SD \\
\hline $\mathrm{R}$-VCL, $\mu \mathrm{m} / \mathrm{s}$ & $228.1^{a}$ & 41.0 & $232.9^{a}$ & 43.4 & $239.6^{a}$ & 14.3 & $259.5^{\mathrm{b}}$ & 22.2 \\
\hline M-VCL, $\mu \mathrm{m} / \mathrm{s}$ & $134.9^{\mathrm{ab}}$ & 15.0 & $129.5^{\mathrm{a}}$ & 8.1 & $132.4^{\mathrm{a}}$ & 9.2 & $140.2^{b}$ & 8.2 \\
\hline $\mathrm{S}-\mathrm{VCL}, \mu \mathrm{m} / \mathrm{s}$ & $63.3^{\mathrm{ab}}$ & 6.7 & $60.5^{\mathrm{a}}$ & 5.1 & $64.8^{\mathrm{b}}$ & 5.0 & $62.9^{a b}$ & 3.7 \\
\hline $\mathrm{R}-\mathrm{VSL}, \mu \mathrm{m} / \mathrm{s}$ & $118.3^{\mathrm{a}}$ & 64.2 & $122.6^{\mathrm{a}}$ & 41.6 & $70.6^{b}$ & 42.5 & $45.8^{c}$ & 14.5 \\
\hline M-VSL, $\mu \mathrm{m} / \mathrm{s}$ & $72.7^{\mathrm{a}}$ & 17.3 & $70.7^{\mathrm{a}}$ & 11.5 & $38.6^{b}$ & 8.5 & $42.2^{b}$ & 10.0 \\
\hline S-VSL, $\mu \mathrm{m} / \mathrm{s}$ & $32.7^{\mathrm{a}}$ & 11.5 & $29.9^{a}$ & 7.5 & $23.6^{b}$ & 7.3 & $28.6^{\mathrm{a}}$ & 7.5 \\
\hline $\mathrm{R}-\mathrm{VAP}, \mu \mathrm{m} / \mathrm{s}$ & $139.4^{\mathrm{a}}$ & 59.7 & $144.8^{\mathrm{a}}$ & 37.4 & $121.0^{\mathrm{ab}}$ & 30.2 & $109.5^{\mathrm{b}}$ & 15.3 \\
\hline $\mathrm{M}-\mathrm{VAP}, \mu \mathrm{m} / \mathrm{s}$ & $87.3^{\mathrm{a}}$ & 16.0 & $85.2^{\mathrm{a}}$ & 11.0 & $67.5^{\mathrm{b}}$ & 6.9 & $73.0^{\mathrm{b}}$ & 7.8 \\
\hline S-VAP, $\mu \mathrm{m} / \mathrm{s}$ & 40.3 & 10.0 & 37.4 & 6.9 & 36.0 & 6.8 & 39.0 & 6.6 \\
\hline R-STR, \% & $80.8^{a}$ & 10.7 & $81.6^{a}$ & 8.9 & $52.4^{\mathrm{b}}$ & 14.7 & $38.2^{c}$ & 7.9 \\
\hline M-STR, \% & $80.3^{a}$ & 8.8 & $81.3^{a}$ & 6.0 & $54.1^{\mathrm{b}}$ & 8.9 & $52.4^{b}$ & 7.6 \\
\hline S-STR, \% & $69.5^{\mathrm{a}}$ & 14.4 & $72.0^{\mathrm{a}}$ & 8.8 & $58.5^{b}$ & 10.6 & $63.5^{b}$ & 10.1 \\
\hline R-LIN, \% & $50.6^{a}$ & 17.1 & $52.5^{\mathrm{a}}$ & 14.9 & $29.4^{b}$ & 17.1 & $17.9^{c}$ & 5.0 \\
\hline M-LIN, \% & $54.2^{\mathrm{a}}$ & 12.8 & $54.8^{\mathrm{a}}$ & 7.8 & $29.5^{b}$ & 7.0 & $31.2^{b}$ & 7.6 \\
\hline S-LIN, \% & $48.6^{a}$ & 15.0 & $47.8^{a}$ & 11.2 & $37.5^{\mathrm{b}}$ & 11.0 & $46.0^{a}$ & 12.5 \\
\hline R-WOB, \% & $59.8^{a}$ & 14.2 & $62.5^{\mathrm{a}}$ & 12.5 & $50.6^{b}$ & 11.7 & $42.5^{\mathrm{c}}$ & 4.3 \\
\hline M-WOB, \% & $65.2^{\mathrm{a}}$ & 11.1 & $66.0^{\mathrm{a}}$ & 6.8 & $52.1^{\mathrm{b}}$ & 4.7 & $52.9^{b}$ & 5.4 \\
\hline S-WOB, \% & 61.6 & 11.7 & 60.7 & 9.4 & 55.9 & 9.5 & 62.0 & 10.4 \\
\hline $\mathrm{R}-\mathrm{ALH}, \mu \mathrm{m}$ & $4.1^{\mathrm{a}} \pm$ & 1.1 & $4.0^{\mathrm{a}}$ & 1.1 & $5.8^{c}$ & 1.2 & $7.3^{\mathrm{b}}$ & 0.6 \\
\hline $\mathrm{M}-\mathrm{ALH}, \mu \mathrm{m}$ & $2.8^{\mathrm{a}}$ & 0.6 & $2.6^{a}$ & 0.3 & $3.8^{\mathrm{b}}$ & 0.5 & $3.6^{\mathrm{b}}$ & 0.7 \\
\hline S-ALH, $\mu \mathrm{m}$ & $1.4^{\mathrm{a}}$ & 0.3 & $1.5^{\mathrm{a}}$ & 0.3 & $1.8^{b}$ & 0.4 & $1.4^{\mathrm{a}}$ & 0.3 \\
\hline $\mathrm{R}-\mathrm{BCF}, \mathrm{Hz}$ & $23.2^{\mathrm{a}}$ & 8.0 & $23.5^{\mathrm{a}}$ & 8.6 & $18.0^{b}$ & 4.6 & $14.6^{b}$ & 3.3 \\
\hline $\mathrm{M}-\mathrm{BCF}, \mathrm{Hz}$ & $27.7^{\mathrm{a}}$ & 4.9 & $28.7^{\mathrm{a}}$ & 3.7 & $18.9^{b}$ & 4.1 & $14.9^{c}$ & 3.7 \\
\hline $\mathrm{S}-\mathrm{BCF}, \mathrm{Hz}$ & $19.1^{\mathrm{a}}$ & 6.0 & $20.8^{a}$ & 3.8 & $15.3^{b}$ & 3.5 & $12.8^{c}$ & 3.8 \\
\hline
\end{tabular}

${ }^{\mathrm{a}-\mathrm{c}}$ Within a row means with a common superscript did not differ at $P=0.05$

R: rapid-swimming sperm, M: medium-swimming sperm, S: slow-swimming sperm, VCL: curvilinear velocity, VSL: straight-line velocity, VAP: average path velocity, STR: straightness, LIN: linearity, WOB: wobble, ALH: amplitude of lateral head displacement, BCF: beat cross frequency

Eight receiver operating characteristic $(\mathrm{ROC})$ curve analysis graphs were constructed. Almost all of the kinematic parameters displayed high sensitivity and specificity values to distinguish between straight-line and hyperactivation swimming tracks (Table 6). Only the VAP parameter had sensitivity and specificity values below $80 \%$ and was thus not regarded as being a restriction. The criterion values of the other seven kinematic parameters were used as cut-off values for Tankwa goat sperm hyperactivation (Table 6). After creating a sort function for Tankwa goats on the SCA motility module using these cut-off values, sperm hyperactivation was calculated automatically and expressed as a percentage of motile spermatozoa.

Procaine hydrochloride caused a high percentage of hyperactivation (25.3\%) compared with the other three media (Table 4). It is clear from Figure 3d that procaine induced typical star-spin patterns, some of which were also detected in lignocaine (Figure 3c), but not often in PBS or BO sperm wash (Figures 3a and $3 b)$. However, there was a large variation $(0-54.5 \%)$ in the percentage hyperactivation induced by procaine in individual semen samples (Figure 4). Percentage sperm hyperactivation was less than $10 \%$ in three males, more than $20 \%$ in seventeen males, and more than $40 \%$ in six males. 
The percentage hyperactivation induced by procaine had a significant positive relationship with semen progressive motility $(r=0.39, P=0.04)$ and rapid-swimming spermatozoa $(r=0.47, P=0.02)$, and VCL in PBS $(r=0.45, P=0.02)$, VAP in PBS $(r=0.40, P=0.04)$ and ALH in PBS $(r=0.50, P=0.01)$.

Table 6 Receiver operating characteristic curve analysis and kinematic parameter restrictions for Tankwa goat hyperactivated spermatozoa

\begin{tabular}{lrcc}
\hline Parameter & Sensitivity & Specificity & Restriction Setting \\
\hline VCL, $\mu \mathrm{m} / \mathrm{s}$ & 94.4 & & $221>\mathrm{VCL}<500$ \\
VSL, $\mu \mathrm{m} / \mathrm{s}$ & 99.3 & 91.8 & $<49.8$ \\
$\mathrm{STR}, \%$ & 100.0 & 98.6 & $<47.2$ \\
LIN, \% & 100.0 & $<15.3$ \\
WOB, \% & 100.0 & 100.0 & $<50.5$ \\
ALH, $\mu \mathrm{m}$ & 97.2 & 97.3 & $5.3>\mathrm{ALH}<15.3$ \\
BCF, Hz & 99.3 & 100.0 & $<23.8$
\end{tabular}

VCL: curvilinear velocity, VSL: straight-line velocity, STR: straightness, LIN: linearity, WOB: wobble, ALH: amplitude of lateral head displacement, BCF: beat cross frequency

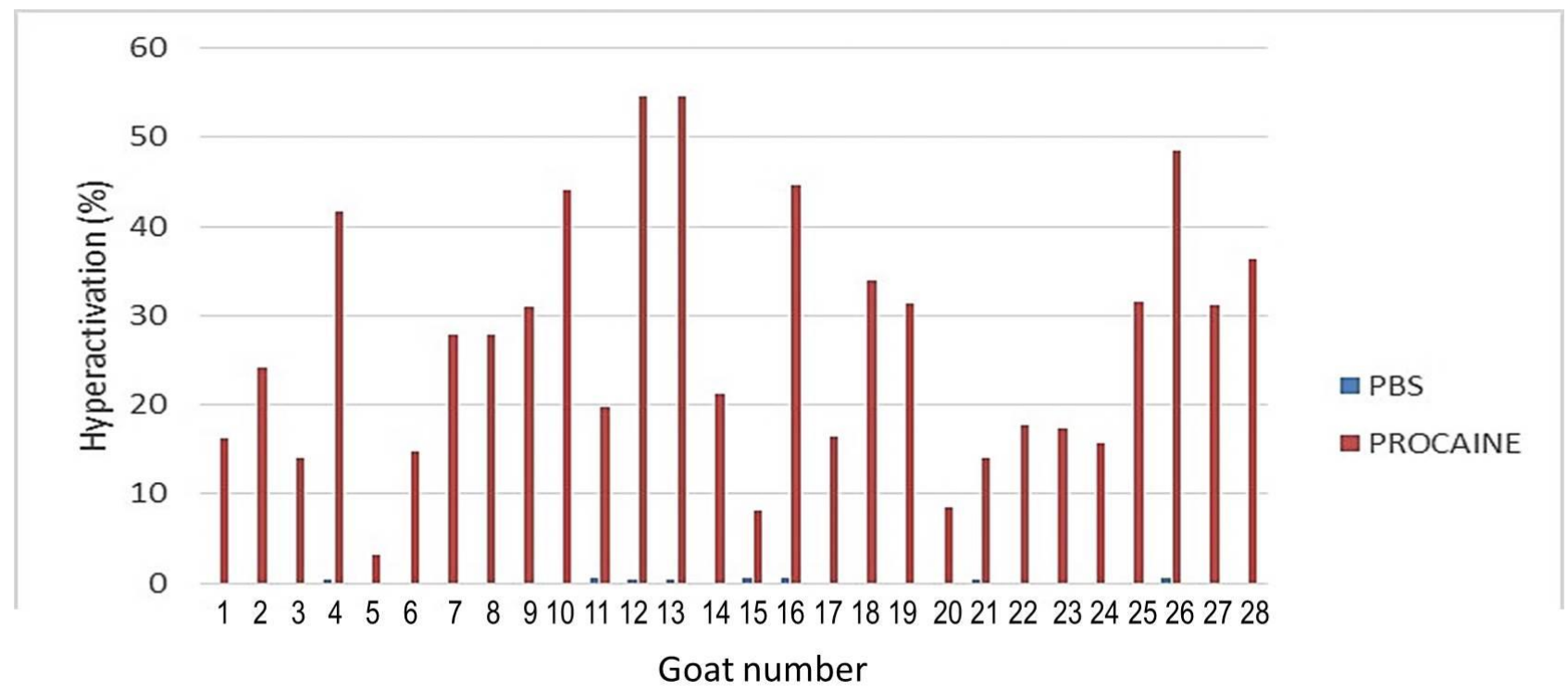

Figure 4 Induced sperm hyperactivation percentage of individual Tankwa goats with the use of phosphate buffered saline and $5 \mathrm{mM}$ procaine hydrochloride $(n=28)$

A large variation was seen in the percentage hyperactivation of individual semen samples with 17 of the samples displaying more than $20 \%$ hyperactivation

PBS: phosphate buffered saline

While any standard semen analysis (CASA or manual) can assist in defining the quality of a semen sample, such an assessment cannot predict fertility per se (Van der Horst \& Du Plessis, 2017). Two advantages of using CASA for evaluation of sperm motility and morphology are that it allows for objective detection of subtle differences among individual spermatozoa and it provides quantitative information on parameters that cannot be assessed manually (e.g. kinematics and subpopulations). Evaluation of sperm subpopulations, such as percentage sperm mucous penetration and hyperactivation, is highly recommended and will determine whether an ejaculate contains sufficient functional spermatozoa to potentially reach and fertilize the oocyte (Mortimer et al., 2015). Four media were also assessed for their effect on sperm motility 
subpopulations and confirmed procaine hydrochloride as an inducer of hyperactivation in Tankwa goat spermatozoa. Procaine achieved the highest percentage sperm hyperactivation (25.3\%), followed by lignocaine (3.4\%), whereas PBS $(0.1 \%)$ and BO sperm wash $(0.04 \%)$ did not induce hyperactivation.

The standard semen parameters of Tankwa goats in the current study are in the same range that was reported for South African indigenous goats (Bopape et al., 2015; Ramukhithi et al., 2018) and for Saanen, Angora, and British goat breeds (Ahmad \& Noakes, 1996; Nur et al., 2005; Talebi et al., 2009). Studies on Norwegian goats (Paulenz et al., 2005) and Florida goats (Hildago et al., 2008) indicated that a highly fertile buck must produce a sperm concentration of $\geq 2000 \times 10^{6} / \mathrm{mL}$. The Tankwa goat thus falls within this range with a mean sperm concentration of $2293.7 \pm 1853.6 \times 10^{6} / \mathrm{mL}$. In the present study, percentages of rapidswimming spermatozoa (12.8 $\pm 11.3 \%$, range $2.6-43.1 \%)$ and normal sperm morphology $(62.0 \pm 26.3 \%)$ were lower than those found by Ramukhithi et al. (2018) for the same Tankwa goat population $(41.2 \pm 5.9 \%$; $93.7 \pm 1.7 \%$ ). This inconsistency is probably owing to a larger sample size, a larger variation in sperm motility and different cut-off values for swimming speed classes in the present study compared with Ramukhithi et al. (2018). Moreover, CASA-derived cut-offs were used in the present study to determine percentage normal morphology, whereas Ramukhithi et al. (2018) scored morphology manually. A recent study, which used a similar approach to assess rat sperm morphometry and morphology reported a similar discrepancy between manually assessed normal morphology (>90\%) and automated analysis (67 - 74\%) (Van der Horst et al., 2018b).

All four of the media investigated in the study supported sperm motility, resulting in high percentages of total motility, which is typical of fertile males from domesticated and wildlife species (Van der Horst et al., 2018a; El Kadili et al., 2019). The percentage progressive sperm motility for most media used in the current study $(40.0$ - $48.9 \%)$ was in agreement with data (44.4 $\pm 6.3 \%)$ reported by Ramukhithi et al. (2018), indicating that lignocaine caused a decrease $(25.4 \%)$ in this motility parameter. The higher percentage rapidswimming spermatozoa and increased values for VCL and ALH indicated that procaine had a stimulatory effect on Tankwa goat sperm motility, which was confirmed in the many rapid-progressive swimming spermatozoa that were visible in captured fields (Figure 3). Although exposure to lignocaine resulted in more asymmetrical and less linear swimming patterns, there was no increase in the swimming speed typical of mammalian hyperactive motility (Van der Horst et al., 2018a). Boye et al. (2019) reported similar decreased progressive motility and LIN in equine spermatozoa after exposure to $100-10000 \mu \mathrm{g} / \mathrm{mL}$ lidocaine, with no induction of hyperactivation. These differences in motility in sperm exposed to lignocaine and procaine justified the use of procaine to determine kinematic cut-off values for Tankwa goat hyperactivation.

The use of cut-off measures for specific sperm head kinematic parameters is a practical and accepted method to define hyperactivated motility in different species (Baumber \& Meyers, 2006; Marquez \& Suarez, 2008). Of these, a decrease in VSL, STR and LIN values and an increase in VCL and ALH are considered hallmarks for hyperactivated spermatozoa (reviewed by Suarez, 2008; Van der Horst et al., 2018a). For instance, Mortimer and Maxwell (1999) reported VCL $(>250 \mu \mathrm{m} / \mathrm{s})$, VSL $(<100 \mu \mathrm{m} / \mathrm{s})$, LIN $(<30 \%)$ and ALH $(>9 \mu \mathrm{m})$, using the Cartesian method, to be indicative of sperm hyperactivation in rams, which is similar to the seven cut-off values used in the present study. In contrast, Colás et al. (2010) induced hyperactivation in ram spermatozoa with caffeine, and used only a decrease in LIN and an increase in ALH as indicators of hyperactivated spermatozoa.

Caffeine (a component of BO sperm wash), lignocaine and procaine (both local anaesthetic agents) have been used to induce hyperactivation in numerous mammalian species by employing various mechanisms of action. Caffeine enhances sperm motility by increasing intracellular calcium by translocation from internal calcium stores (Hong et al., 1985; Ho \& Suarez, 2001) or by inhibiting phosphodiesterase, which results in increased cyclic adenosine monophosphate and protein kinase A levels (Garbers et al., 1971; Bender \& Beavo, 2006). Lignocaine has been shown to cause an increase in the concentration of intracellular $\mathrm{Ca}^{2+}$ in sensory neurons from influx through the plasma membrane and release from $\mathrm{Ca}^{2+}$ internal stores (Gould et al., 1998) and to cause sperm hyperactivation in human sperm (Bennett et al., 1992). Hyperactivation induced by procaine has been associated with a moderate increase in intracellular $\mathrm{pH}$, which could activate CatSper channels, followed by influx of extracellular $\mathrm{Ca}^{2+}$ (Carlson et al., 2003; Kirichok et al., 2006; Ortgies et al., 2012), or could be directly linked to inhibition of sodium influx (Leemans et al., 2018). Interestingly, procaine-induced hyperactivation in the stallion (Loux et al., 2013) and guinea-pig (Mújica et al., 1994) was shown to be independent of external $\mathrm{Ca}^{2+}$, which is similar to the present results (procaine in PBS).Whereas procaine induced on average $25.3 \%$ hyperactivation in Tankwa goat spermatozoa, this was lower than the $73 \%$ reported in equine spermatozoa (McPartlin et al., 2009) and the $64 \%$ in guinea pig spermatozoa (Mújica et al., 1994). These differences could be because of interspecies differences, the physical environment in which spermatozoa swim, and the kinematic parameters that were used to establish threshold values for hyperactivated spermatozoa (Suarez \& Ho, 2003; Van der Horst et al., 2018a). 
An average of $25 \%$ hyperactivation for Tankwa goats suggested a fertile goat population, since it corresponded to the more than $20 \%$ hyperactivation found in other normospermic mammalian samples and human sperm with fertilizing ability (Mortimer \& Mortimer, 1990; Van der Horst et al., 2018a). In fact, more than $60 \%$ of the individual Tankwa goat samples portrayed more than $20 \%$ hyperactivation, albeit a range of $0-54 \%$ was recorded for the 28 individual semen samples that were assessed. Although this could be an indication of inter-individual variability in sperm functional capabilities and the ability to compete with the spermatozoa of another male, it must be taken into account that only a certain population of spermatozoa will present with the quadrilateral CatSper1 domain organization that is needed to become hyperactivated or capacitated at a certain time Chung et al. (2014). Because the percentage hyperactivation induced in the present study correlated with the percentages of progressive and rapid-swimming spermatozoa and VCL and VAP, this indicates that semen samples with high percentage motility would contain sufficient spermatozoa that could become hyperactivated.

\section{Conclusions}

The novel approach in this study was to determine cut-off values for kinematic parameters for hyperactivation using CASA combined with ROC curve analysis. After exposing highly motile spermatozoa from semen to various media, PBS and BO sperm wash maintained sperm motility, but were unsuccessful in inducing hyperactivation in Tankwa goat spermatozoa. It is recommended that procaine hydrochloride should be used in future evaluations of potential male fertility in this species. Further, it should be regarded as a rapid diagnostic tool for similar assessments in other animal species. The use of hyperactivation as a test of sperm function might distinguish between breeding and non-breeding males and assist animal production specialists to select males with high sperm functionality.

\section{Acknowledgements}

This work was supported financially by the National Research Foundation (grant number 87940) and the Northern Cape Department of Agriculture, Land Reform and Rural Development (DALRRD). The authors would also like to thank DALRRD for their technical assistance.

\section{Authors' Contributions}

AN conducted the research as part of her MSc project and was responsible for the first draft of the manuscript. LM and GvdH contributed to the original ideas of the study and revised the manuscript. AK and TJ as collaborators commented on the revised manuscript.

\section{Conflict of Interest Declaration}

The authors report no conflict of interest.

\section{References}

Ahmad, N. \& Noakes, D.E., 1995. Seasonal variations in testis size, libido and plasma testosterone concentrations in British bucks. Anim. Sci. 61, 553-559. DOI: 10.1017/S1357729800014132

Alasmari, W., Barratt, C., Publicover, S., Whalley, K., Foster, E., Kay, V., da Silva, S. M. \& Oxenham, S., 2013. The incidence and clinical significance of defects in calcium signalling pathways mediating human sperm hyperactivation in donors and sub fertile patients. Hum. Reprod. 28, 886-876. DOI: 10.1093/humrep/des467

Ardon, F., Markello, R.D., Hu, L., Deutsch, Z.I., Tung, C., Wu, M. \& Suarez, S.S., 2016. Dynamics of bovine sperm interaction with epithelium differ between oviductal isthmus and ampulla. Biol. Reprod. 95, 90. DOI: 10.1095/biolreprod.116.140632

Baumber, J. \& Meyers, S.A., 2006. Hyperactivated motility in rhesus macaque (Macaca mulatta) spermatozoa. J. Androl. 27, 459-68. DOI: 10.2164/jandrol.05107

Bedu-Addo, K., Costello, S., Harper, C., Machado-Oliveira, G., Lefievre, L., Ford, C., Barratt, C. \& Publicover, S., 2008. Mobilisation of stored calcium in the neck region of human sperm - a mechanism for regulation of flagellar activity. Int. J. Dev. Biol. 52, 615-626. DOI: 10.1387/ijdb.072535kb

Bender, A.T. \& Beavo, J.A., 2006. Cyclic nucleotide phosphodiesterases: Molecular regulation to clinical use. Pharmacol. Rev. 58, 488-520. DOI: 10.1124/pr.58.3.5

Bennett, S.J., Bolton, V. \& Parsons, J., 1992. The effects of lignocaine on human sperm motility. J. Ass. Reprod. Gen. 9, 271-273.

Bopape, M.A., Lehloenya, K.C., Chokoe, T.C. \& Nedambale, T.L. 2015. Comparison of electro ejaculator and artificial vagina on semen collection from South African indigenous goat following assessment by computer aided sperm analysis. Open J. Anim. Sci. 5, 210-218. DOI: 10.4236/ojas.2015.52023

Boshoff, N.H., Lambrechts, H., Maree, L., Cloete, S.W.P. \& Van der Horst, G., 2018. A novel flush technique to stimulate natural dispersal of spermatozoa in the female reproductive tract and expedite motility assessment of freshly ejaculated Merino (Ovis aries) sperm. S. Afr. J. Anim. Sci. 48, 469-476. DOI: 10.4314/sajas.V.4813.7

Boye, J.K., Katzman, S.A., Kass, P.H. \& Dujovne, G.A., 2019. Effects of lidocaine on equine ejaculated sperm and epididymal sperm post-castration. Theriogenology 134, 83-89. DOI: 10.1016/j.theriogenology.2019.05.009

Brackett, B.G. \& Oliphant, G., 1975. Capacitation of rabbit spermatozoa in vitro. Biol. Reprod. 12, $260-274$. 
Carlson, A.E., Westenbroek, R.E., Quill, T., Ren, D., Clapham, D.E., Hille, B., Garbers, D.L. \& Babcock, D.F., 2003. CatSper1 required for evoked $\mathrm{Ca} 2+$ entry and control of flagellar function in sperm. Proc. Natl. Acad. Sci. USA 100, 14864-14868. DOI: 10.1073/pnas.2536658100

Chung, J.J., Shim S.H., Everley, R.A., Gygi, S.P., Zhuang, X. \& Clapham, D.E., 2014. Structurally distinct $\mathrm{Ca}^{2+}$ signalling domains of sperm flagella orchestrate tyrosine phosphorylation and motility. Cell 157, 808-822. DOI: 10.1016/j.cell.2014.02.056

Coetzee, K., Bermes, N., Krause, W. \& Menkveld, R., 2001. Comparison of normal sperm morphology outcomes from two different computer-assisted semen analysis systems. Andrologia 33,159-163. DOI: 10.1046/j.14390272.2001.00421.x

Colás, C., Cebri'án-Pérez, J.A. \& Muiño-Blanco, T., 2010. Caffeine induces ram sperm hyperactivation independent of CAMP dependent protein kinase. Int. J. Androl. 33, 187-197. DOI: 10.1111/j.1365-2605.2009.00991.x

Costello, S., Michelangeli, F., Nash, K., Lefievre, L., Morris, J., Machado-Oliveira, G., Barratt, C., Kirkman-Brown, J. \& Publicover, S., 2009. $\mathrm{Ca}^{2+}$-stores in sperm: their identities and functions. Reproduction 138, 425-437. DOI: 10.1530/REP-09-0134

DeLong, E.R., DeLong, D.M. \& Clarke-Pearson, D.L., 1988. Comparing the areas under two or more correlated receiver operating characteristic curves: a nonparametric approach. Biometrics 44, 837-845.

El Kadili, S., Raes, M., Bister, J.L., Archa, B., Chentouf, M. \& Kirschvink, N., 2019. Effect of season on sexual behavior, testicular measurements and seminal characteristics in Beni arouss North Moroccan bucks. Anim. Reprod. Sci. 201, 41-54. DOI: 10.1016/j.anireprosci.2018.12.007

Garbers, D.L., Lust, W.D., First, N.L. \& Lardy, H.A., 1971. Effects of phosphodiesterase inhibitors and cyclic nucleotides on sperm respiration and motility. Biochemistry 10, 1825-1831. DOI: 10.1021/bi00786a015

Gravance, C.G., Lewis, K.M. \& Casey, P.J., 1995. Computer automated sperm head morphometry analysis (ASMA) of goat spermatozoa. Theriogenology 44, 989-1002. DOI: 10.1016/0093-691X(95)00286-H

Gervasi, M.G. \& Visconti, P.E., 2016. Chang's meaning of capacitation: A molecular perspective. Mol. Reprod. Dev. 83, 860-874. DOI: 10.1002/mrd.22663

Gould, K.G., Young, L.G. \& Hinton, B.T., 1988. Alterations in primate sperm motility with maturation and during exposure to theophylline. Am. J. Primatol. 15, 325-336. DOI: 10.1002/ajp.1350150406

Henkel, R. Maaß, G., Bödeker, R.H., Scheibelhut, C., Stalf, T., Mehnert, C., Schuppe, H.C., Jung, A. \& Schill, W.B., 2005. Sperm function and assisted reproduction technology. Reprod. Med. Biol. 4, 7-30. DOI: 10.1111/j.14470578.2005.00087.x

Hildago, M., Rodriguez, I. \& Dorado, J., 2008. The effect of cryopreservation on sperm head morphometry in Florida male goat related to sperm freezability. Anim. Reprod. Sci. 100, 61-72. DOI: 10.1016/j.anireprosci.2006.07.003

Ho, H.C. \& Suarez, S.S., 2001. An inositol 1, 4, 5-trisphosphate receptor-gated intracellular Ca2+ store is involved in regulating sperm hyperactivated motility. Biol. Reprod. 65, 1606-1615. DOI: 10.1095/biolreprod65.5.1606

Ho, H.C. \& Suarez, S.S., 2003. Characterization of the intracellular calcium store at the base of the sperm flagellum that regulates hyperactivated motility. Biol. Reprod. 68, 1590-1596. DOI: org/10.1095/biolreprod.102.011320

Hong, C.Y., Chiang, B.N., Wu, P., Wei, Y.H. \& Fong, J.C., 1985. Involvement of calcium in the caffeine stimulation of human sperm motility. Br. J. Clin. Pharmacol. 19, 739-743. DOI: 10.1111/j.1365-2125.1985.tb02708.x

Hunter, R.H., 2012. Components of oviduct physiology in eutherian mammals. Biol. Rev. Camb. Philos. Soc. 87, 244255. DOI: 10.1111/j.1469-185X.2011.00196.x

Kirichok, Y., Navarro, B. \& Clapham, D.E., 2006. Whole-cell patch-clamp measurements of spermatozoa reveal an alkaline-activated Ca2+ channel. Nature 439, 737-740. DOI: 10.1038/nature04417

Kotze, A., Grobler J.P, Van Marie-Korster E., Jonker T. \& Dalton D.L., 2014. The Tankwa Karoo National Park feral goat population: A genetic unique population. S. Afr. J. Anim. Sci. 44, 43-48. DOI: 10.4314/sajas.v44i1.6

Leemans, B., Gadella, B.M., Stout, T.A.E. \& Van Soom, A., 2018. Procaine induces hyperactivated motility in stallion spermatozoa by inhibiting sodium influx. J. Equine Vet. Sci. 66, 23.

Loux, S.C., Crawford, K.R., Ing, N.H., Gonzalez-Fernandez, L., Macias-Garcia, B., Love, C.C., Varner, D.D., Velez, I.C., Choi, Y.H. \& Hinrichs, K., 2013. CatSper and the relationship of hyperactivated motility to intracellular calcium and pH kinetics in equine sperm. Biol. Reprod. 89, 123. DOI: 10.1095/biolreprod.113.111708

Malejane, C.M., Greyling, J.P.C. \& Raito, M.B., 2014. Seasonal variation in semen quality of Dorper rams using different collection techniques. S. Afr. J. Anim. Sci., 44, 26-32. DOI: 10.4314/sajas.v44i1.4

Maree, L. \& Van der Horst, G., 2013. Quantification and identification of sperm sub-populations using computer-aided sperm analysis and species-specific cut-off values for swimming speed. Biotech. Histochem. 3-4, 181-193. DOI: 10.3109/10520295.2012.75736

Marquez, B. \& Suarez, S. S., 2008. Bovine sperm hyperactivation is promoted by alkaline-stimulated $\mathrm{Ca}^{2+}$ influx. Biol. Reprod. 76, 660-665. DOI: 10.1095/biolreprod.106.055038

McPartlin, L.A., Suarez, S.S., Czaya, C.A., Hinrichs, K. \& Bedford-Guaus, S.J., 2009. Hyperactivation of stallion sperm is required for successful in vitro fertilization of equine oocytes. Biol. Reprod. 81, 199-206. DOI: 10.1095/biolreprod.108.074880

Mortimer, D., 1994. Practical laboratory andrology. Oxford University Press, New York.

Mortimer, D., Mortimer, S. \& Van der Horst, G., 2015. The future of computer-aided sperm analysis. Asian J. Androl. 17, 545-553. DOI: 10.4103/1008-682X.154312

Mortimer, S.T., 1997. A critical review of the physiological importance and analysis of sperm movement in mammals. Hum. Reprod. Update 3, 403-439. DOI: 10.1093/humupd/3.5.403

Mortimer, S.T. \& Maxwell, W,M., 1999. Kinematic definition of ram sperm hyperactivation. Reprod. Fertil. Dev. 11, 25-30. DOI: $10.1071 /$ rd99019 
Mortimer, S.T. \& Mortimer, D., 1990. Kinematics of human spermatozoa incubated under capacitating conditions. J. Androl. 11, 195-203.

Mucina, L. \& Rutherford, M.C., 2006. The vegetation of South Africa, Lesotho and Swaziland, Strelitzia 19. South African National Biodiversity Institute. Pretoria.

Mújica, A., Neri-Bazan, L., Tash, J.S. \& Uribe, S., 1994. Mechanism for procaine-mediated hyperactivation motility in guinea pig spermatozoa. Mol. Reprod. Dev. 38, 285-292. DOI: 10.1002/mrd.1080380309

Ncube, K.T., Mdladla, K., Dzomba, E.F. \& Muchadeyi, F.C., 2016. Targeted high-throughput growth hormone 1 gene sequencing reveals high within-breed genetic diversity in South African goats. Anim. Genet. 47, 382-385. DOI: 10.1111/age.12424

Noakes, D.E., Parkinson, T.J. \& England, G.C.W., 2009. Veterinary reproduction and obstetrics. Saunders, China.

Nur, Z., Dogan, I., Gunay, U.\&Soylu, M.K., 2005. Relationships between sperm membrane integrity and other semen quality characteristics of the semen of Saanen goat bucks. Bull. Vet. Inst. Pulawy 49, 183-187.

Ortgies, F., Klewitz, J., Gorgens, A., Martinsson, G. \& Sieme, H., 2012. Effect of procaine, pentoxifylline and trolox on capacitation and hyperactivation of stallion spermatozoa. Andrologia 44,130-138. DOI: 10.1111/j.14390272.2010.01150.x

Paulenz, H., Soltun, K., Ådnøy, T. Berg K.A. \& Söderquist, L., 2005. Effect of different extenders on sperm viability of buck semen stored at room temperature. Small Ruminant Res. 59, 89-94.

Puga Molina, L.C., Luque, G.M., Balestrini, P.A., Marín-Briggiler, C.I., Romarowski, A. \& Buffone, M.G. 2018. Molecular basis of human sperm capacitation. Front. Cell Dev. Biol. 6, 72. DOI: 10.3389/fcell.2018.00072

Ramukhithi F.V., Nephawe K.A., Lehloenya K.C., Seshoka M.M, Jonker T., Kotze A., Chokoe T.C. \& Nedambale T.L., 2018. Characterization of seminal plasma constituents of unimproved indigenous and Tankwa goats. S. Afr. J. Anim. Sci. 48, 943-953. DOI: 10.4314/sajas.v48i5.14

Strünker, T., Goodwin, N., Brenker, C., Kashikar, N.D., Weyand, I., Seifert, R. \& Kaupp, U.B., 2011. The CatSper channel mediates progesterone-induced $\mathrm{Ca} 2+$ influx in human sperm. Nature 471, 382-386. DOI: 10.1038/nature09769

Suarez, S.S., 2008. Regulation of sperm storage and movement in the mammalian oviduct. Int. J. Dev. Biol. 52, 445-462. DOI: $10.1387 / \mathrm{ijdb} .072527 \mathrm{ss}$

Suarez, S.S. \& Wu, M., 2017. Microfluidic devices for the study of sperm migration. Mol. Hum. Reprod. 23, 227-234. DOI: 10.1093/molehr/gaw039

Sumigama, S., Mansell, S., Miller, M., Lishko, P.V., Cherr, G.N., Meyers, S.A. \& Tollner, T., 2015. Progesterone accelerates the completion of sperm capacitation and activates CatSper channel in spermatozoa from rhesus macaque. Biol. Reprod. 93, 130. DOI: 10.1095/biolreprod.115.129783

Talebi, J., Souri, M., Moghaddam, A., Karimi, I. \& Mirmahmoodi, M., 2009. Characteristics and seasonal variation in the semen of Markhoz bucks in Western Iran. Small Ruminant Res. 85, 18-22. DOI: 10.1016/j.smallrumres.2009.06.017

Tamburrino, L., Marchiani, S., Vicini, E., Muciaccia, B., Cambi, M., Pellegrini, S., Forti, G., Muratori, M. \& Baldi, E., 2015. Quantification of CatSper1 expression in human spermatozoa and relation to functional parameters. Hum. Reprod. 30, 1532-1544. DOI: 10.1093/humrep/dev103

Van der Horst, G. \& Maree, L., 2009. SpermBlue: A new universal stain for human and animal sperm which is also amenable to automated sperm morphology analysis. Biotech. Histochem. 84, 299-308. DOI: $10.3109 / 10520290902984274$

Van der Horst, G. \& Du Plessis, S.S., 2017. Not just the marriage of Figaro: but the marriage of WHO/ESHRE semen analysis criteria with sperm functionality. Adv. Androl. Online 4, 6-21.

Van der Horst, G., Maree, L. \& du Plessis, S.S. 2018a. Current perspectives of CASA applications in diverse mammalian sperm. Reprod. Fertil. Dev. 30, 875-888. DOI: 10.1071/RD17468

Van der Horst, G., Skosana, B., Legendre, A., Oyeyipo, I.P. \& du Plessis, S.S., 2018b. Cut-off values for normal sperm morphology and toxicology for automated analysis of rat sperm morphology and morphometry. Biotech. Histochem. 93, 49-58. DOI: 10.1080/10520295.2017.1380842

Verstegen, J., Iguer-Ouada, M. \& Onclin, K., 2002: Computer assisted semen analyzers in andrology research and veterinary practice. Theriogenology 57, 149-179. DOI: 10.1016/s0093-691x(01)00664-1

Visconti, P.E., Krapf, D., de la Vega-Beltrán, J.L., Acevedo, J.J. \& Darszon, A., 2011. Ion channels, phosphorylation and mammalian sperm capacitation. Asian J. Androl. 13, 395-405. DOI: 10.1038/aja.2010.69

Williams, H.L., Mansell, S., Alasmari, W., Brown, S.G., Wilson, S.M., Sutton, K.A., Miller, M.R., Lishko, P.V., Barratt, C.L.R., Publicover, S.J. \& Martins da Silva, S., 2015. Specific loss of CatSper function is sufficient to compromise fertilizing capacity of human spermatozoa. Hum. Reprod. 30, 2737-2746. DOI:

Yanagimachi, R., 1994. Mammalian fertilization. In: E. Knobil \& J.D. Neill (eds). The physiology of reproduction. Raven Press, New York, pp. 189-317. 